\title{
Views of Adults on Shopping Trolleys: Implications for the Development of a Shopping Trolley
}

\author{
Enid W.Y. Kwong ${ }^{*}, 1$, Claudia K.Y. Lai ${ }^{1}$, Ernesto Spicciolato ${ }^{2}$ and Martin C.M. Wong ${ }^{3}$ \\ ${ }^{1}$ School of Nursing, The Hong Kong Polytechnic University, Yuk Choi Road, Hung Hom, Hong Kong \\ ${ }^{2}$ School of Design, The Hong Kong Polytechnic University, Yuk Choi Road, Hung Hom, Hong Kong \\ ${ }^{3}$ Industrial Centre, The Hong Kong Polytechnic University, Yuk Choi Road, Hung Hom, Hong Kong
}

\begin{abstract}
Expert recommendations regarding trolley specifications and customer expectations of trolley features are equally important in the development of a customer-oriented shopping trolley that minimizes the risk of musculoskeletal injuries. However, little is known about such customer expectations, and hence this study aimed to examine the views of Hong Kong adults on shopping trolleys.

A cross-sectional survey was conducted with a sample of 140 Chinese adults aged 40 or over with no cognitive or communication impairments. These adults were approached in markets, supermarkets, and public parks in Hong Kong. Individual face-to-face interviews using a questionnaire were used to collect the data.

Fifty-six (40\%) of the participants were current users, 32 (23\%) were ex-users, and 52 (37\%) were non-users of shopping trolleys. More of the user and ex-user participants perceived shopping trolleys to be energy saving and protective of the joints. Lightness and easy storage, a pulling and pushing motion, suitability for use on stairs, and adjustable handle height were the trolley features most frequently expected by the participants. The user and ex-user participants rated lightness, a pushing motion and changeable trolley bags to be comparatively more important than the non-user participants.

The findings have implications for the development of an evidence-based shopping trolley design. Close cooperation is needed between ergonomists and design and engineer experts to develop an ergonomically designed shopping trolley that prioritizes the health and safety of its users.
\end{abstract}

Keywords: Shopping trolley, customer expectations.

\section{INTRODUCTION}

Different types of trolleys are produced for various markets. These trolleys usually carry a name that reflects their purpose, for example truck trolley, rickshaw, golf trolley, cage, and shopping trolley. Shopping trolleys are commonly used in shopping for the transportation of large amounts of food and materials to save energy and minimize potential musculoskeletal injuries caused by the manual handling of heavy loads. However, poorly designed trolleys do not achieve this function. Instead, they may cause injury to users, such as pain and stiffness in the neck, shoulders, and upper and lower extremities [1], and lumbosacral [2-3] and back injuries [4]. Market research on 30 shopping trolleys conducted by our research team indicates that most shopping trolleys are poorly designed, for example with nonadjustable handle heights and a lack of pushing motion that increases the force that users must exert and the mechanical loading on their lower back, shoulders, and spine [4-6]. This suggests that there is a need to develop a trolley that not only minimizes possible design-induced musculoskeletal injuries but is also acceptable to potential users. In developing such a trolley, recommendations on trolley specifications from

*Address correspondence to this author at the School of Nursing, The Hong Kong Polytechnic University, Yuk Choi Road, Hung Hom, Hong Kong; Tel: +852-27666385; E-mail: hsenid@inet.polyu.edu.hk experts and potential users' expectations of trolley features are equally important. However, to the best of our knowledge, the latter have been hitherto ignored, creating a gap in the literature. We thus conducted a survey to examine the views of Hong Kong adults on shopping trolleys that are customer-owned and kept at home. Our study findings should inform the development of an evidence-based shopping trolley design that is guided by customer requirements.

\subsection{Study Objectives}

- Identify ex-users' and non-users' reasons for not using trolleys.

- Identify perceptions of trolleys among users, ex-users, and non-users.

- Identify the perceived importance of various trolley features among users, ex-users, and non-users.

- $\quad$ Examine differences in age, gender, perceptions, and perceived importance among users, ex-users, and non-users.

\section{LITERATURE REVIEW}

\subsection{Professional View}

Professional organizations, product companies, and researchers have all recommended designs for the wheels, 
handles, direction of motion, and weight of carts to enhance their efficiency and decrease users' musculoskeletal risks. The government of the Canadian province of Alberta [7] suggested that carts with larger wheels are more stable, particularly when used over rough surfaces and in narrow gaps. Carts with large wheels reduce the average force required from users and lessen their physical stress [8-10]. Speed is another benefit of large wheels, as reported by Drury's team [11]. Their study showed that wheels with a 25 $\mathrm{cm}$ diameter were $16 \%$ faster than those with a $7.5 \mathrm{~cm}$ diameter. Carts with four wheels are preferable because they eliminate the friction force between the wheels and the floor [12]. It has also been recommended that the force that users need to exert to change the direction of travel can be reduced by using swivel wheels. Without swivel wheels, carts have to be moved in an arc to turn [13]. Al-Eisawi and his colleagues suggested [14] using four swivel wheels for carts, because the rear swivel wheels increase the pushing speed and the front swivel wheels require $10 \%$ less pushing or pulling force on the part of the user [11].

Handles for carts should be of suitable height to reduce the force required from users and the mechanical loading on their lower back, shoulders [5], and joints [15]. Previous studies have reported that the higher the handles, the greater the force required [16-17] and the shearing force [18]. The Alberta government [7] recommended that the handle should be at a height between the elbow and hip for pushing and between the hip and knee for pulling for optimal push and pull force capabilities. Type of handle also significantly influences the amount of force exerted. Thomas et al. [19] revealed that a low friction aluminum handle could decrease the pull or push force exertion by $17 \%$ compared with a high friction rubber handle. In addition, pull or push capabilities were increased by $22 \%$ when the long axis of the handle was perpendicular.

Direction of motion in carts is another health and safety concern. Pushing carts is safer and less hazardous to the spine than pulling. The torque and compression at the L4/5 vertebrae with a pushing motion is often greater than that with a pulling motion. A pulling motion may also cause the cart also to run over users' feet, strike their ankles, and force them to stretch their arms behind their bodies, all of which increase the risk of pain and injury [20].

Empirical data has found that an increase in cart weight is associated with greater energy expenditure, increased pulmonary ventilation, and an increased heart rate in users $[4,21]$. When the weight of the cart is increased, users are more likely to lean more forward, causing higher compression and shearing force to their lower back [22]. However, there are no recommendations for shopping trolleys in the literature.

\subsection{User Views}

In the study of Mack et al. [23], users commented on 14 types of manual handling aids, including two- and fourwheeled industrial trolleys. They found that the aids were unstable and difficult to control, especially when they were moved around cracks, steps, or specific types of floor. In addition, inappropriate handle heights caused them to bend their torso to use the aids, which led to further stress on their lower back muscles. Watson [24] collected feedback from users of shopping trolleys and found that they preferred a lightweight shopping trolley with larger wheels that had an aluminum rather than a steel frame that is lighter in weight. Although these two studies give some data on users' expectation of trolleys, only Watson specifically investigated shopping trolleys, and he only targeted users. To develop a customer-oriented shopping trolley, key features of a shopping trolley from views of users, ex-users and non-users should be known but no studies had been explored this area. A research question of this study is " what are customers" expected features of a shopping trolley?"

\section{METHODOLOGY}

\subsection{Sampling}

This was a cross-sectional survey with a convenience sample of 140 participants recruited from 10 markets, 10 supermarkets, and 10 public parks in Hong Kong Island, Kowloon, and the New Territories. The participants were Chinese, aged 40 years or over, voluntarily agreed to participate in the study, and had no apparent communication or cognitive impairments in the professional judgment of the data collectors, who were registered nurses.

\subsection{Questionnaire}

A questionnaire was developed by our research team based on a previous focus group study. In the focus group study, six groups with a total of 27 participants aged 40 or above (3-6 participants in each group) were recruited from three public parks in Kowloon and the New Territories. Qualitative content analysis of the focus group data identified three categories, including reasons for not using shopping trolleys, perceptions of shopping trolleys, and perceived importance of trolley features. The research team developed the questionnaire for this survey based on these categories. The questionnaire consisted of five parts: sociodemographics, usability of shopping trolleys, reasons for not using shopping trolleys, perceptions of shopping trolleys, and perceived importance of trolley features. The last three parts measured participants' views on shopping trolleys. The questionnaire was content validated $(\mathrm{CVI}=0.95)$ by three experts in product development and geriatric care, and the inter-rater agreement among 10 data collectors with 10 participants was $100 \%$.

\subsection{Ethical Considerations}

Our study was approved by the Human Subjects Ethics Subcommittee of the University. Informed verbal consent was obtained from all of the participants before the data collection was started. The participants were assured that there would be no penalties if they refused to cooperate with any of the procedures or withdrew from the study at any time. It was also guaranteed that the confidentiality of the data would be strictly protected.

\subsection{Procedures}

Before the data collection, the inter-rater agreement among the 10 data collectors was established. Each data collector followed the data collection protocol prepared by our research team to collect data in one public park, one supermarket, and one market in Hong Kong Island, Kowloon, or the New Territories. The data collectors approached individuals who were present in the study 
settings, and screened out those who did not meet the selection criteria by asking their age and professionally judging their communicative ability and cognitive function. After obtaining informed verbal consent, the data collectors asked the participants the questionnaire items and filled in their responses on the questionnaire sheet. Forty-seven $(33.6 \%)$ participants were recruited from supermarkets, 45 $(32.1 \%)$ from markets, and $48(34.3 \%)$ from public parks.

\subsection{Data Analysis}

The data were analyzed using the Statistical Package for the Social Sciences (SPSS) version 15.0. Descriptive statistics were used to analyze the frequency of the study variables. The Chi-square test was used to examine the differences in gender, age, and perceptions of shopping trolleys, whereas independent t-test examined the differences in perceived importance in trolley features among users, exusers, and non-users. The statistical significance value was set at $\mathrm{p} \leq 0.05$.

\section{RESULTS}

\subsection{Characteristics of the Sample and Usage of Shopping Trolleys}

Of the 140 participants, $52(37 \%)$ were male and 59 $(42 \%)$ were aged 65 or over. Fifty-six $(40 \%)$ participants were current users, $32(23 \%)$ were ex-users, and $52(37 \%)$ were non-users of shopping trolleys. Compared with the exusers $\left(\chi^{2}=7.776, p=0.009\right)$ and non-users $\left(\chi^{2}=24.014\right.$, $\mathrm{p}<0.000)$, a greater proportion of the current users $(86 \%)$ were female (Table 1).

Many users and ex-users used or had used trolleys once or twice per week (59\%) for 1-2 hours each time $(50 \%)$ for buying food (44\%) and shopping (34\%) in markets $(40 \%)$ and supermarkets $(34 \%)$ when the roadway conditions were dry and even (36\%) (Table 2).

\subsection{Reasons of Ex-users and Non-users for not Using Trolleys}

The three most reported reasons for not using shopping trolleys were not needing to buy many things, the inconvenience of carrying a trolley during shopping, and living near a market or shopping center (Table $\mathbf{3}$ ).

\subsection{Perception of Trolleys}

Most of the users perceived that trolleys helped to save energy $(n=55,98.3 \%)$ and protected their joints $(n=52$, $92.9 \%$ ). The three most frequently reported perceptions of trolleys among non-users were that it was not necessary to use them $(n=43,82.7 \%)$, they were an energy-saving device $(n=35,67.3 \%)$, and they were an assistive device for elderly people $(n=34,65.4 \%)$. Compared with the non-users, more of the users and ex-users perceived shopping trolleys to be light and convenient (users: $\chi^{2}=25.48, \mathrm{p}<0.000$; ex-users: $\chi^{2}=9.89, \mathrm{p}=0.003$ ), energy-saving (users: $\chi^{2}=18.54, \mathrm{p}<0.000$; ex-users: $\chi^{2}=10.29, \mathrm{p}=0.001$ ), and protective to joints (users: $\chi^{2}=19.78, \mathrm{p}<0.000$; ex-users: $\left.\chi^{2}=7.29, \mathrm{p}=0.009\right)$. However, more non-users than users $\left(\chi^{2}=18.167, \mathrm{p}=0.000\right)$ and exusers $\left(\chi^{2}=5.572, p=0.023\right)$ thought that trolleys were unnecessary (Table 4).

\subsection{Perceived Importance of Various Trolley Features}

Both the participants with (users and ex-users) and without (non-users) experience in using trolleys perceived that lightness, durability, and easy storage and having the functions of a pulling and pushing motion, suitability for use on stairs, and adjustable handle height were more important than other factors in considering the purchase of a trolley. Compared with the participants without experience of using trolleys, those with experience rated factors such as lightness $(\mathrm{t}=2.601, \mathrm{p}=0.011)$, the pushing motion function $(\mathrm{t}=2.145$, $\mathrm{p}=0.034)$, and changeable trolley bags $(\mathrm{t}=2.252, \mathrm{p}=0.027)$ to be higher in importance (Table 5). There were no gender $(p=0.42)$ or age $(p=0.32)$ differences in the perceived importance of the features.

\section{DISCUSSION}

This study aimed to explore the views of adults on shopping trolleys. Around two-thirds of our sample had either current or previous experience in using shopping trolleys. Women were more likely to be current users. When performing traditional or conventional family roles, women have more opportunities to shop and to purchase goods in large quantities, for example food and household wares, than their male counterparts. Female adults also have a higher percentage of body fat but less muscle mass and bone than male adults, and so tend to use trolleys for assistance in

Table 1. Gender and Age Differences Among Users, Ex-Users, and Non-Users

\begin{tabular}{|c|c|c|c|c|c|c|c|c|c|c|c|}
\hline & \multicolumn{2}{|c|}{ Total } & \multicolumn{2}{|c|}{ Users } & \multicolumn{2}{|c|}{ Ex-Users } & \multicolumn{2}{|c|}{ Non-Users } & \multirow{2}{*}{$\begin{array}{c}\text { Users and } \\
\text { Ex-Users } \chi^{2}(p)\end{array}$} & \multirow{2}{*}{$\begin{array}{c}\text { Users and } \\
\text { Non-Users } \chi^{2}(p)\end{array}$} & \multirow{2}{*}{$\begin{array}{c}\text { Ex-Users and } \\
\text { Non-Users } \chi^{2}(p)\end{array}$} \\
\hline & $\mathbf{N}$ & $(\%)$ & $\mathbf{n}$ & $(\%)$ & $\mathrm{n}$ & $(\%)$ & $\mathrm{n}$ & $(\%)$ & & & \\
\hline \multicolumn{12}{|l|}{ Gender } \\
\hline Male & 52 & $37 \%$ & 8 & $14 \%$ & 13 & $41 \%$ & 31 & $60 \%$ & \multirow{2}{*}{$7.776(0.009)^{* *}$} & \multirow{2}{*}{$24.014(0.000)^{* *}$} & \multirow{2}{*}{ NS } \\
\hline Female & 88 & $63 \%$ & 48 & $86 \%$ & 19 & $59 \%$ & 21 & $40 \%$ & & & \\
\hline \multicolumn{12}{|l|}{ Age } \\
\hline $55-64$ & 40 & $29 \%$ & 15 & $27 \%$ & 6 & $19 \%$ & 19 & $37 \%$ & & & \\
\hline $65-74$ & 22 & $16 \%$ & 8 & $14 \%$ & 5 & $16 \%$ & 9 & $17 \%$ & & & \\
\hline$>75$ & 37 & $26 \%$ & 17 & $30 \%$ & 10 & $31 \%$ & 10 & $19 \%$ & & & \\
\hline
\end{tabular}


Table 2. Usage of Shopping Trolleys Among Users and ExUsers $(\mathbf{n}=\mathbf{8 8})$

\begin{tabular}{|c|c|c|}
\hline Items & $\mathbf{n}$ & $\%$ \\
\hline \multicolumn{3}{|c|}{ Frequency of Usage (Per Week) } \\
\hline $1-2$ times & 52 & $59 \%$ \\
\hline 3-4 times & 26 & $30 \%$ \\
\hline $5-6$ times & 7 & $8 \%$ \\
\hline$>7$ times & 3 & $3 \%$ \\
\hline \multicolumn{3}{|c|}{ Duration of Usage Each Time } \\
\hline$<1$ hour & 25 & $29 \%$ \\
\hline $1-2$ hours & 44 & $50 \%$ \\
\hline 3-4 hours & 15 & $16 \%$ \\
\hline$>4$ hours & 4 & $5 \%$ \\
\hline \multicolumn{3}{|l|}{ Reason for Usage } \\
\hline Shopping & 46 & $34 \%$ \\
\hline Buying food & 61 & $44 \%$ \\
\hline Carrying things home & 9 & $7 \%$ \\
\hline Porter & 21 & $15 \%$ \\
\hline \multicolumn{3}{|l|}{ Location of Usage } \\
\hline Supermarket & 48 & $34 \%$ \\
\hline Market & 58 & $40 \%$ \\
\hline Shopping mall & 22 & $15 \%$ \\
\hline Department store & 6 & $4 \%$ \\
\hline On the way home & 10 & $7 \%$ \\
\hline \multicolumn{3}{|c|}{ Common Roadway Conditions in which Trolley was Used } \\
\hline Dry even & 65 & $36 \%$ \\
\hline Wet even & 26 & $14 \%$ \\
\hline Dry uneven & 18 & $10 \%$ \\
\hline Wet uneven & 15 & $8 \%$ \\
\hline Sloped path & 27 & $15 \%$ \\
\hline Scupper & 10 & $5 \%$ \\
\hline Stairs & 22 & $12 \%$ \\
\hline
\end{tabular}

transporting items. Elderly people are perceived to be relatively less able to carry heavy loads than younger adults, and so tend to be users of shopping trolleys, but in our sample there was no significant difference in age among trolley users. Rather, trolley use depended on whether the participants needed to carry heavy things a long distance. However, frequent or prolonged manual lifting of loads, even if they are not particularly heavy, can cause musculoskeletal pain and injury because of the repetitive movements of the joints, twisting of the body, and stooping [25]. At-risk populations should thus be educated and encouraged to use shopping trolleys. People who have had experience in using trolleys are more likely to comment positively on their specific benefits, such as their weight, convenience, and load-carrying capability. This indicates the contribution of trolley use to better health.

The data on perceived importance of trolley features among the users and non-users in our study give a good indication of customer expectations of trolley features. Customers expect a light, durable, and easy-to-store trolley with the functions of a pulling and pushing motion, suitability for use on stairs, and an adjustable handle height. Hong Kong is a small city that covers an area of 425 square miles and has a population of 7 million [26], so it is understandable that easy storage is an expected trolley feature. Other expected features, including lightness, a pushing motion function, and an adjustable handle height, decrease the risk of injuries and musculoskeletal pain, and for these reasons are also recommended by professional organizations, product companies, and researchers $[5,20$, 22]. Trolleys suitable for use on stairs are commonly operated by a pair of three-grouped rear wheels, but only work with a pulling motion, which is likely to increase the risk of musculoskeletal strain. Detachable shopping trolley bags were reported to be less important features, but the participants with experience in trolley use were more likely to report this feature as being important than those without such experience. The participants with experience in trolley use may have experienced the disadvantages of permanently attached bags, such as the difficulty of cleaning them and the

Table 3. Ex-Users' and Non-Users' (n=84) Reasons for Not Using Trolleys

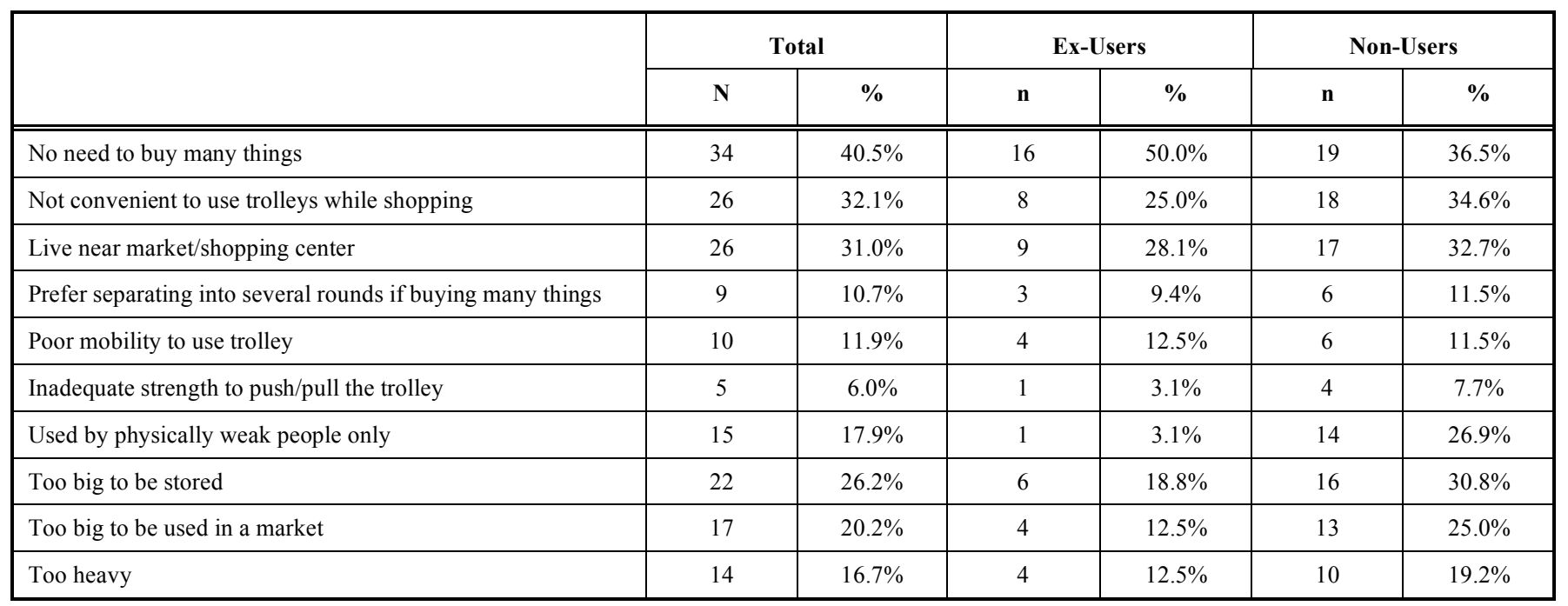


Table 4. Perceptions of Trolleys Among Users, Ex-Users, and Non-Users ( $=140)$

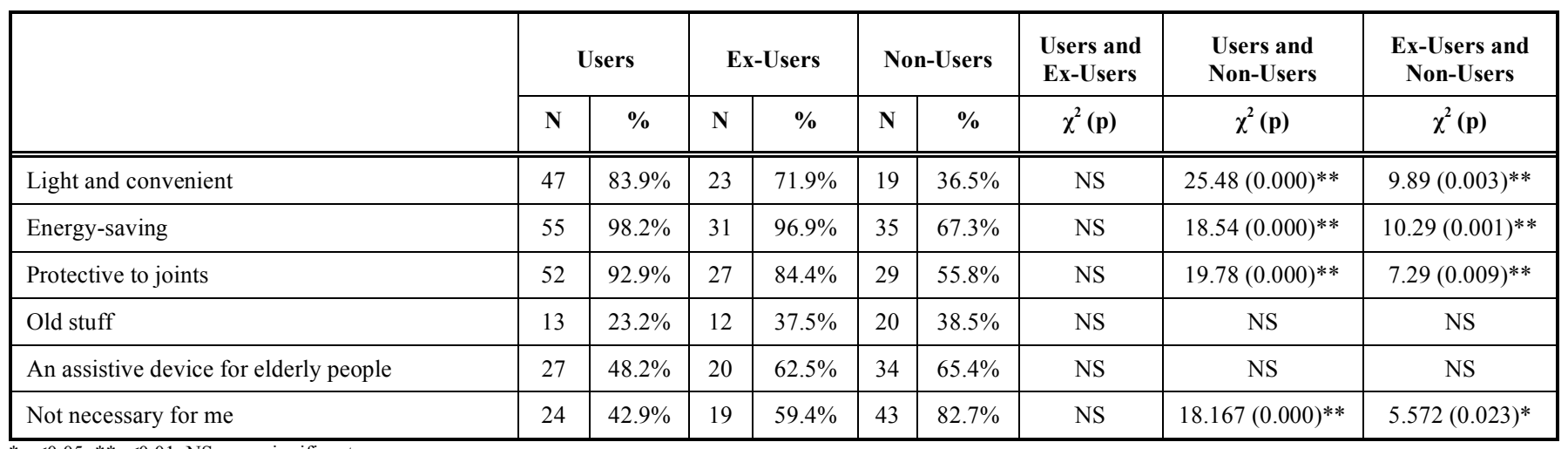

${ }^{*} \mathrm{p} \leq 0.05 ; * * \mathrm{p} \leq 0.01, \mathrm{NS}=$ non-significant.

Table 5. Perceived Importance of Trolley Features Among Participants with and without Experience of Trolley Use

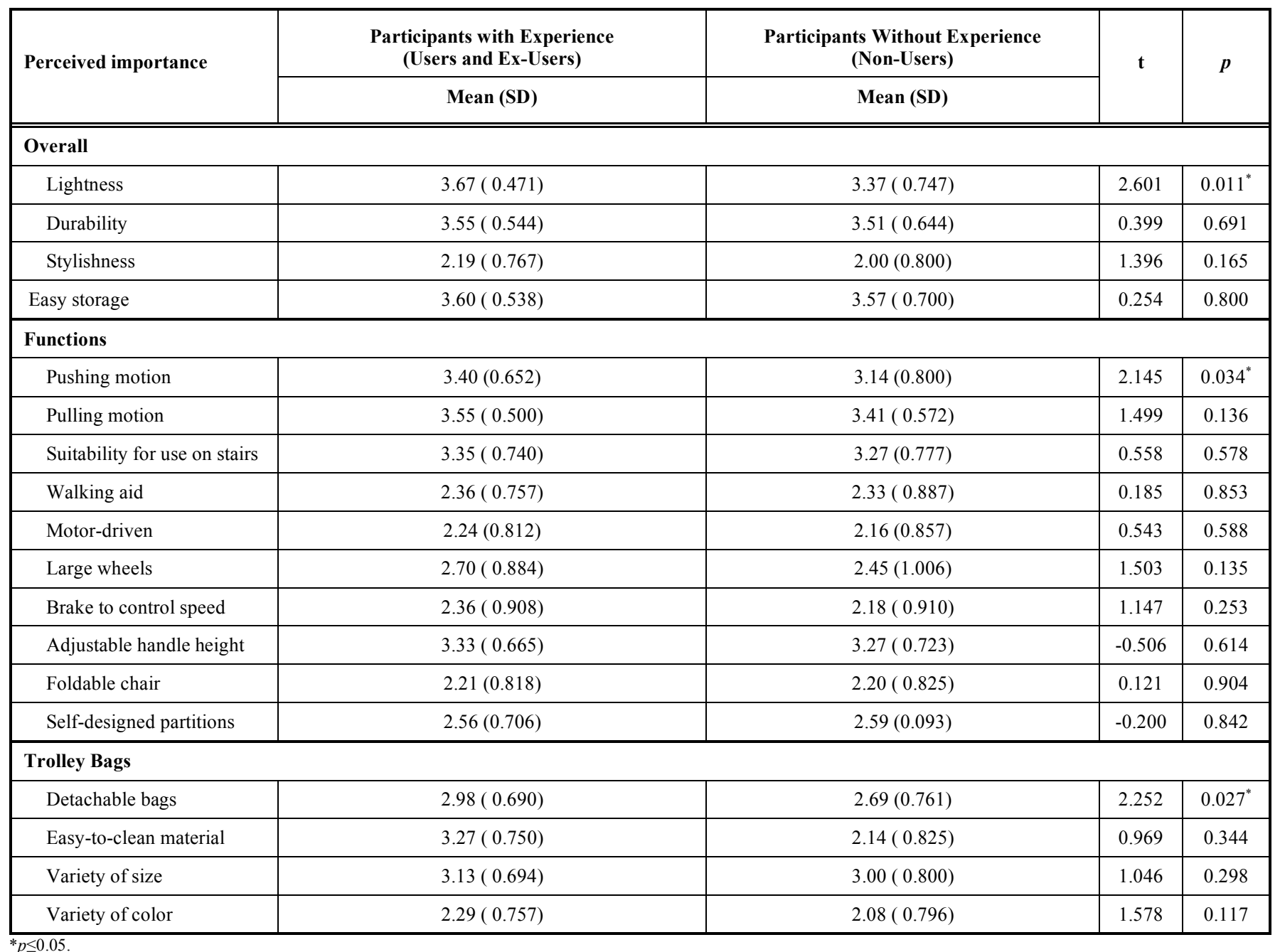

necessity of buying a new trolley because of an old or broken bag.

Knowledge of the individual trolley feature expected by customers is not new, but a previous market search indicates that no available trolleys have all of the expected features identified in this study combined in one product. We thus suggest close collaboration between ergonomists and experts from the healthcare, design, and engineering fields to develop a customer-oriented and ergonomically designed trolley that has all of these expected features. The literature on recommended designs to minimize the risk of musculoskeletal pain and injury $[7,10,14,19,20]$ indicates that such a trolley would also have a foldable aluminum frame for easy storage, large swivel wheels for pulling and pushing, specially designed wheels for climbing up and 
down stairs, a telescopic handle to adjust the height, and a detachable trolley bag with a stylish design.

\section{CONCLUSION}

This study is the first to investigate customer views on shopping trolleys. The convenience sample limits the generalizability of the study, and the findings are thus applicable only to adults with similar characteristics to those of our study sample in Hong Kong or other similar cities. However, the results have implications for the development of an ergonomically designed trolley that is acceptable to adults in Hong Kong and other similar cities. Future studies are recommended to develop this trolley and evaluate its efficiency with a sample of adults in the community.

\section{ACKNOWLEDGEMENTS}

This study was supported by the Dean's Research Fund, the Faculty of Health and Social Sciences, the Hong Kong Polytechnic University and Bunhoi Co. Limited.

\section{REFERENCES}

[1] van der Beek AJ, Frings-Dersen MHW, van Dijk FJH, Kemper HCG, Meijman TF. Loading and unloading by lorry drivers and musculoskeletal complaints. Int J Ind Ergon 2003; 12: 13-23.

[2] Garg A, Moore JS. Epidemiology of low-back pain in industry. Occup Med: State Art Rev 1992; 7: 593-608.

[3] Manning DP. Deaths and incidents caused by slipping, tripping and falling. Ergonomics 2003; 26: 3-9.

[4] Hoozemans MJM, van der Beek AJ, Frings-Dresen MHW, van Dijk FJH, van der Woude LHV. Pushing and pulling in relation to musculoskeletal disorders: a review of risk factors. Ergonomics 2005; 41(6): 757-81.

[5] Kuijer PFM, Hoozemans MJM, Frings-Dresen MHW. A different approach for the ergonomic evaluation of pushing and pulling in practice. Int J Ind Ergon 2007; 37(11-12): 855-62.

[6] Schibye B, Sogaard K, Martinsen D, Klausen K. Mechanical load on the low back and shoulders during pushing and pulling of twowheeled waste containers compared with lifting and carrying of bags and bin. Clin Biomech 2001; 16: 549-59.

[7] Government of the Canadian Province of Alberta. Workplace health and safety. Occupational Health and Safety Magazine: Ergonomics 2004; 1-4.

[8] Hoozemans MJM, van der Beek AJ, Fringe-Dresen MHW. Pushing and pulling in relation to musculoskeletal complaints. Proceedings of the XIVth Triennial Congress of the International Ergonomics Association and $44^{\text {th }}$ Annual Meeting of the Human Factors and Ergonomics Society, July 29 - August 4, San Diego, CA, USA 2000; pp. 4-284.

[9] Young SL, Brogmus GE, Bezverkhny I. The forces required to pull loads up stairs with different hand trucks. Proceedings of the
Human Factors and Ergonomics Society $41^{\text {st }}$ Annual Meeting. Human Factors and Ergonomics Society. Santa Monica, CA 1997; pp. 697-701.

[10] Das B, Wimpee J. Ergonomics evaluation and redesign of a hospital meal cart. Appl Ergonomics 2002; 33: 309-18.

[11] Drury CG, Barnes RE. Pedestrian operated vehicles in hospitals. Proceedings of the $26^{\text {th }}$ Spring Annual Conference and World Productivity Congress, American Institute of Industrial Engineers, Norcross, GA 1975; pp. 184-91.

[12] Jung MC, Haight JM, Freivalds A. Pushing and pulling carts and two-wheeled hand trucks. Int J Ind Ergon 2005; 35: 79-89.

[13] State Fund. Measuring Push/Pull Forces on Carts. 2004 (retrieved November 10, 2009) available from http://www.scif.com/safety/ ergomatters/Carts.html.

[14] Al Eisawi KW, Kerk CJ, Congleton JJ, Amendola AA, Jenkins OC, Gaines W. Factors affecting minimum push and pull forces of manual carts. Appl Ergonomics 1999; 30: 235-245.

[15] Kuiper JI, Burdorf A, Verbeek HAM, Frings-Dresen MHW. van der Beek AJ, Viikari-Juntura ERA. Epidemiological evidence on manual materials handling as a risk factor for back disorders: a systematic review. Int J Ind Ergon 1999; 24(4): 389-404.

[16] Lee KS, Chaffin DB, Herrin GD, Walker AM. Effect of handle height on lower-back loading in cart pushing and pulling. Appl Ergonomics 1991; 22: 117-123.

[17] Lee KS, Chaffin DB, Herrin GD. Walker AM. A study of slip potential during cart pushing and pulling. IIE Transactions 1992; 24(5): 139-146.

[18] Gagnon M, Delisle A, Desjardines P. Biomechanical differences between best and worst performance in repeated free asymmetrical lifts. Int J Ind Ergon 2002; 29(2): 73-83.

[19] Thomas NJS, Armstrong J, Dannecker KL. The effect of friction and arm posture on maximum pull or push force. 2007 (retrieved November 12, 2009) available from http://www.asbweb.org/conf erences/2007/163.pdf.

[20] National Institute of Occupational Safety and Health. Ergonomic Guidelines for Manual Material Handling. NIOSH Publication 2007; p. 131

[21] Datta SR, Chatterjee BB, Roy BN. The energy cost of rickshaw pulling. Ergonomics 1978; 21: 879-886.

[22] Laursen B, Schibye B. The effect of different surfaces on biomechanical loading of shoulder and lumbar spine during pushing and pulling of two-wheeled containers. Appl Ergonomic 2002; 33: 167174.

[23] Mack K, Haslegrave CM, Gray MI. Usability of manual handling aids for transporting materials. Appl Ergonomics 1995, 26: 353364.

[24] Waston M. Shopping Trolley Project - Eco Design Project. Institute of Australian (2004)

[25] Canada's National Occupational Health and Safety Resource. Pushing and Pulling-Handcarts. 1997 (retrieved November 12, 2009) Available from http://www.ccohs.ca/oshanswers/ergonom ics/push2.html.

[26] Census and Statistics Department. Hong Kong Statistics. 2009 (retrieved October 12, 2009) available from http://www.censtatd. gov.hk/hong_kong_statistics/statistics_by subject/index.jsp 